\author{
Military Technical College \\ Cairo, Egypt
}

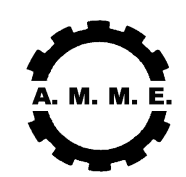

$12^{\text {th }}$ International Conference on Applied Mechanics and Mechanical Engineering (AMME)

\title{
THE MECHANICAL BEHAVIOUR OF RECYCLED HIGH DENSITY POLYETHYLENE
}

\author{
ALI* A.A., Abo El-Khair* M.S.
}

\begin{abstract}
In last few years with the increasing use of polymeric materials the disposal of the used material became a serious problem. As polyethylene is one of the common used polymers in many applications it represents a significant amount of the total municipal waste of thermoplastic materials. Thus recycling process of polyethylene is a subject which needs more investigation. Hence in the present work an experimental investigation of the mechanical properties was carried out on virgin and recycled/virgin high density polyethylene (HDPE) to study the effect of three successive generations of HDPE as well as of the amount of recycled material added to the virgin one on the density, tensile, impact, and creep properties.
\end{abstract}

The results showed that with recycling the HDPE three times, the density as well as the modulus of elasticity, the percentage elongation, the impact strength, and the recovery percentage of the HDPE decrease while the tensile strength increases. With increasing the recycled to virgin ratio of HDPE the density, the impact strength, and the recovery percentage increase while the modulus of elasticity, the percentage elongation, and the tensile strength remain almost constant.

\section{KEY WORDS}

Polyethylene, recycling, recovery, mechanical properties, and moulding. 


\section{INTRODUCTION}

Rare materials, such as gold and silver, are recycled because acquiring new supplies is expensive. Other materials may not be as expensive to replace, but they are recycled for another reasons.

Recycling helps in land conservation; landfills fill up quickly and acceptable sites for new ones are difficult to find because of objections by neighbors to noise and smell. The major way to reduce the need for new sites is to recycle wastes. Also recycling a product creates less pollution than producing a new one, which reduces the number of pollution-related illnesses. From the economic point of view, recycling reduces the need for raw materials and conserves energy by reducing the need to process new material, which usually requires more energy than recycling [1].

The increased interest in plastics recycling has resulted from three important trends. First the increase of the production and use of plastics, as shown in Table 1. Second, the resin prices have increased dramatically. Third, growing concern about the quality of the environment has led to more restrictive disposal regulations.

Table 1. Projections of materials generated in MSW stream, 1995:2010 [2]

\begin{tabular}{|r|c|c|c|}
\hline \multirow{2}{*}{ Materials } & \multicolumn{3}{|c|}{$\%$ of total generation } \\
\cline { 2 - 4 } & 1995 & 2000 & 2010 \\
\hline Paper and paper board & 42.8 & 44.5 & 48.4 \\
\hline Food and yard wastes & 23.1 & 22.1 & 19.9 \\
\hline Plastics & 9.3 & 9.8 & 10.3 \\
\hline Total metals & 8.1 & 7.8 & 7 \\
\hline Glass & 5.6 & 4.8 & 3.8 \\
\hline Wood & 3.7 & 3.9 & 4.1 \\
\hline Others & 7.3 & 7.2 & 6.6 \\
\hline
\end{tabular}

Some factors can adversely affect the quality of recycled plastics. These factors include the possible degradation of the plastic during its original life cycle and the possible addition of foreign materials to the recycled plastic during the recycling process. But the main problem remains how to sort the different types of plastics.

There are well-established processes for recycling metals and ceramics, but the recycling of plastics scrap has not developed to a comparable extent. The higher densities of metals and ceramics make it easier to separate these materials from other components of an industrial or municipals waste stream. Polymer scrap, on the other hand, is difficult to recover once it has been mixed into a waste stream [3]. So, plastics are more difficult to recycle than metal, paper, or glass. While about $35 \%$, $40 \%$, and $25 \%$ of Aluminum, paper, and glass products, respectively, were recycled in United States, only about 5\% of plastics were recycled in 1994. 
Most modern automated plastic sorting systems are not capable of differentiating between many types of plastics. However, some progression is being made in these systems to separate plastics by color, density, and chemical composition. For example, X-ray sensors can distinguish PET from PVC by sensing the presence of chlorine atoms in PVC material [1].

One of the successful systems for identifying plastic containers by plastic type is "chasing arrows". It appears on the bottom of many plastic containers to promote plastic recycling. The chasing arrows enclose a number (such as 1 indicating PET, 2 indicating HDPE, 3 indicating PVC) which aids plastic sorting process, Fig. 1 [2].

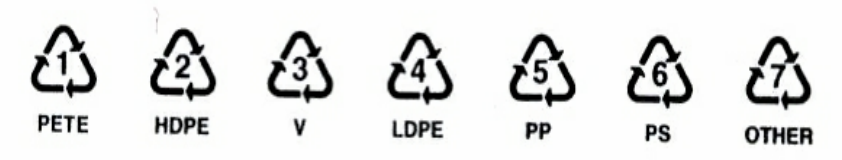
1. PETE $=$ POLYETHYLENE TEREPHTHALATE (PET)
2. $\quad$ HDPE $=$ HIGH-DENSTTY POLYETHYLENE
3. $\quad \mathrm{V}=$ VINYL/POLYVINYL CHLORIDE (PVC)
4. $\quad$ LDPE $=$ LOW-DENSTTY POLYETHYLENE
5. $\quad P P=$ POLYPROPYLENE
6. $\quad$ PS $=$ POLYSTYRENE
7. OTHER

Fig. 1. SPI code system: Voluntary guidelines for plastic bottle and container material code system [2]

Another problem facing the process of plastics recycling is following rules of thumb which recommend recycled plastic usage, usually $25 \%$ or less by weight. These rules are very conservative, and are not based on sound experimentation [4]. It was shown in a previous study on LDPE [5], that despite the loss of the mechanical properties in the recycling process, the properties found were still greater than many other virgin thermoplastics.

Polyethylene is by far the most extensively used plastic material and accounted for $35 \%$ of the total sales in the United States in 1993. The main reason for its prime position is that, it is low in cost and has many industrial important properties: high toughness at room temperature and also at lower temperatures with sufficient strength, good flexibility over a wide range of temperatures even down to $-73^{\circ} \mathrm{C}$, excellent corrosion resistance, excellent insulating properties, odorless and tasteless [6]. So, HDPE is a commonly used material for containers, pipes, electrical insulation, chemical tubing, house wears, and blow-moulded bottles. More recently some other applications were introduced like cement powder plants, drainage, petrochemical plants, utility conduits and swimming pools.

The recycled HDPE can be applied in several products, such as: soft-drink bottle base caps, flowerpots, drainpipes, stadium seats, traffic barrier cones, golf bag liners, detergent bottles, and toys. 
The aim of the present experimental work is to study the mechanical properties namely, elasticity modulus, yield strength, percentage elongation, Charpy impact strength, creep and recovery behaviour, and density of virgin HDPE under normal conditions and to study the effect of recycled material percentage and recycling generations.

\section{EXPERIMENTAL WORK}

\subsection{Material and Processing}

The tested material is high density polyethylene in granulated form made in Egypt (under license of BP Chemicals). It was produced in August 2002 by SIDPEC Company for Petrochemicals and commercially named "Egyptene" with degree HD6070UA 219.

First of all, a steel die, Fig. 2, was designed and manufactured to produce HDPE standard specimens in dimensions according to ASTM D638M-93 [7] for tensile specimens and ES 895-1967 [8] for impact specimens. All the specimens was injected in the "Factory of Plastic Packages for Armed Forces". A Battenfeld injection moulding machine model BSKM 45/23 was used, Fig. 3. The recycling processes were carried out in the same place by using a Chinese crusher model SCP-640 and a spring recycling \& blending M/C model SEVB-85 as shown in Figs. 4 and 5 respectively.

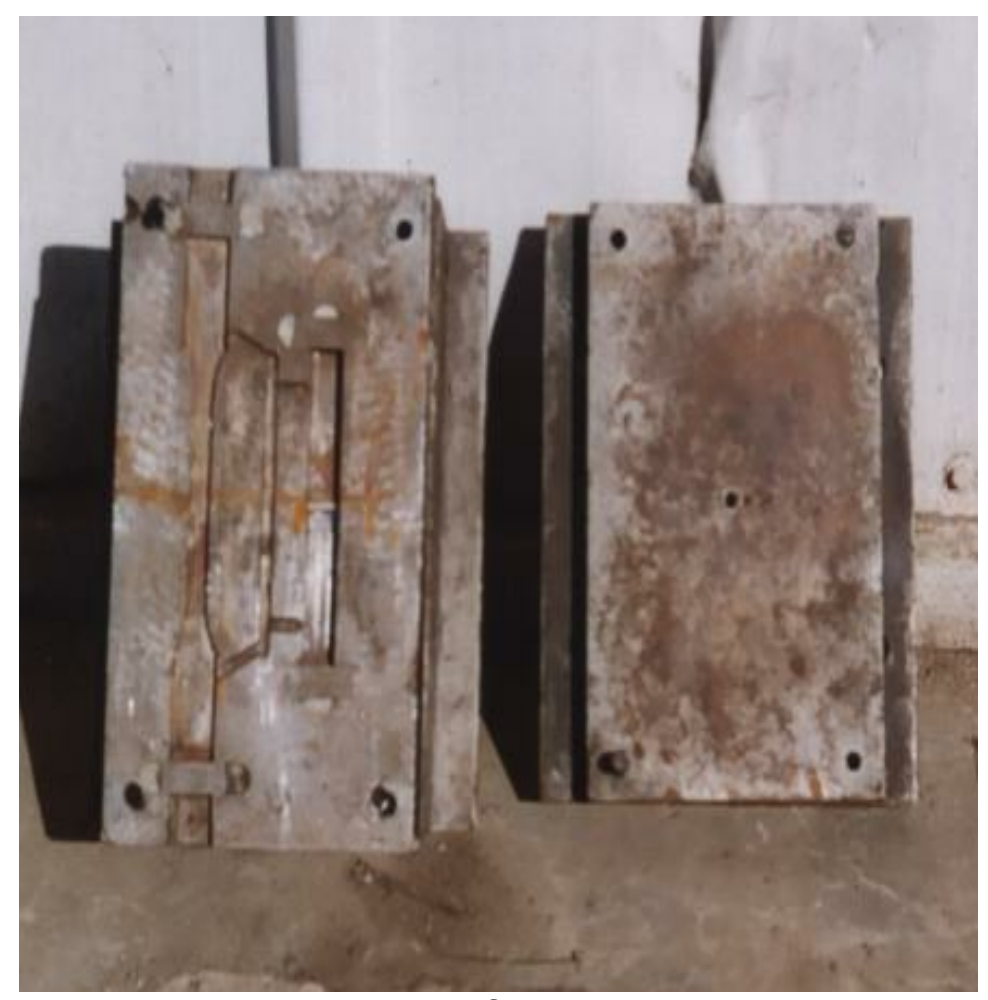

Fig. 2. The manufactured steel die 


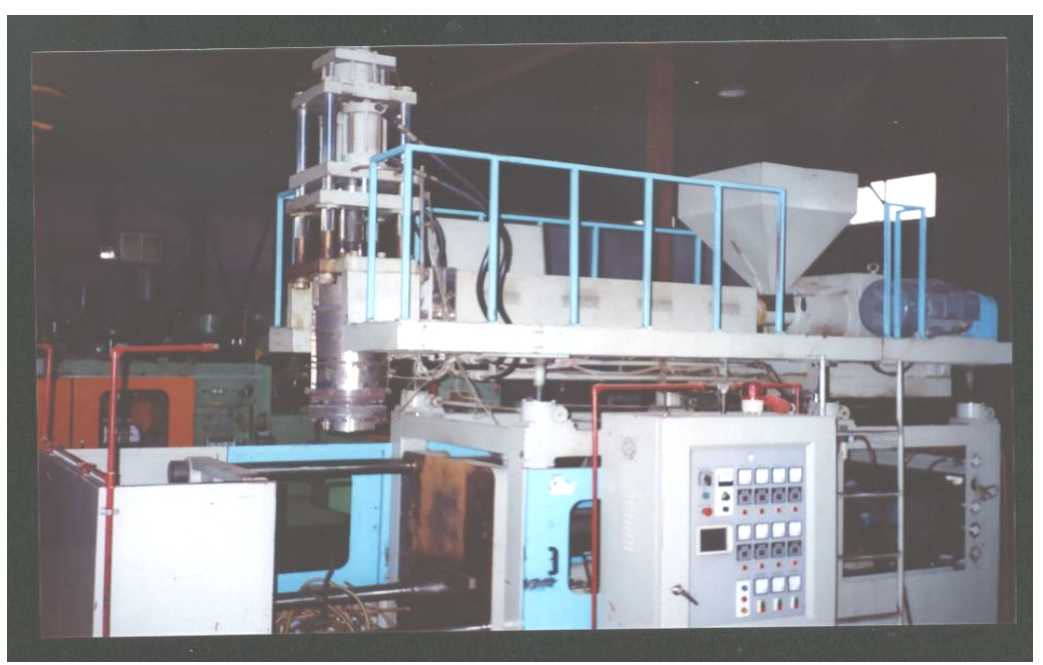

Fig. 3. The injection machine

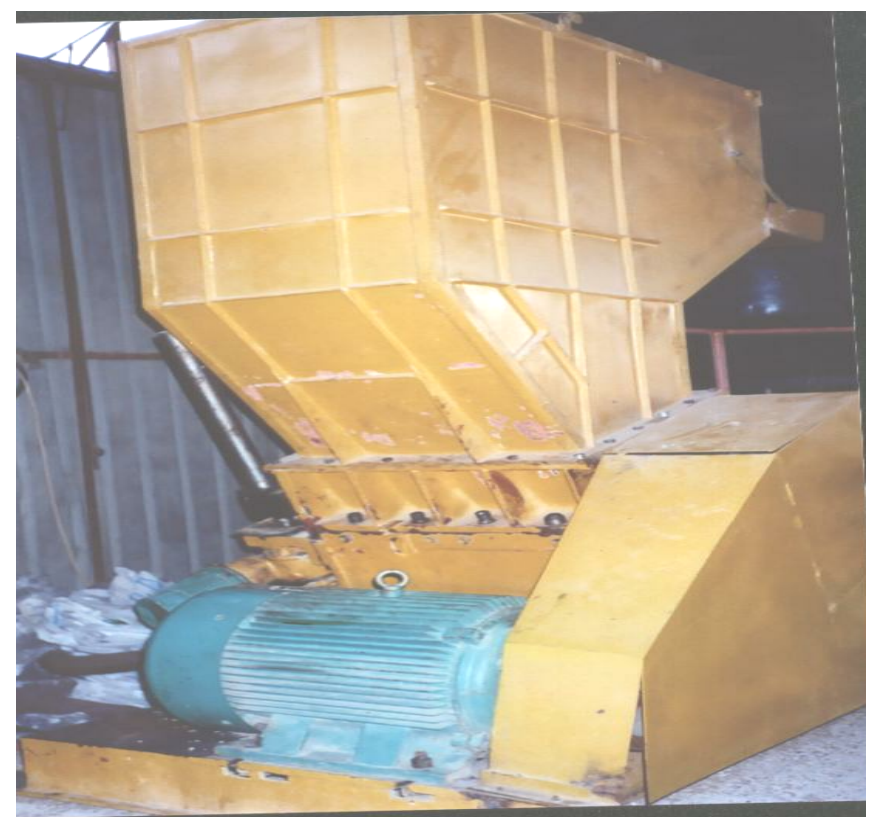

Fig. 4. The plastics crusher

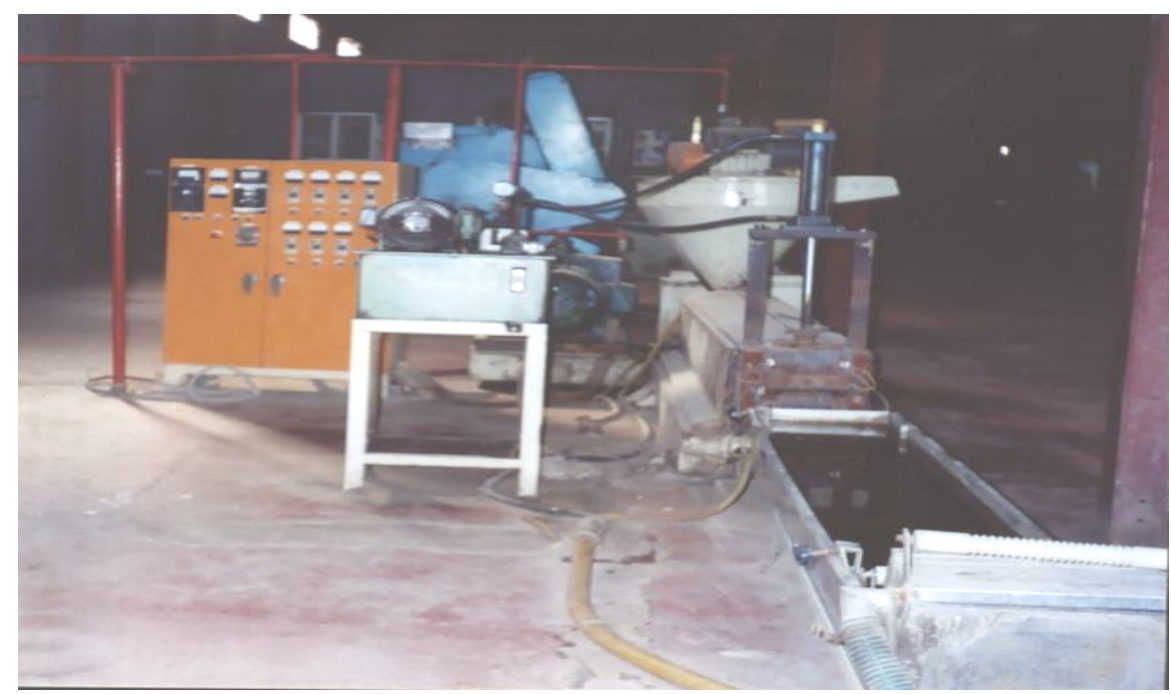

Fig. 5. The recycling line 
The following chart represents a summary of the experimental tests carried out on HDPE specimens.
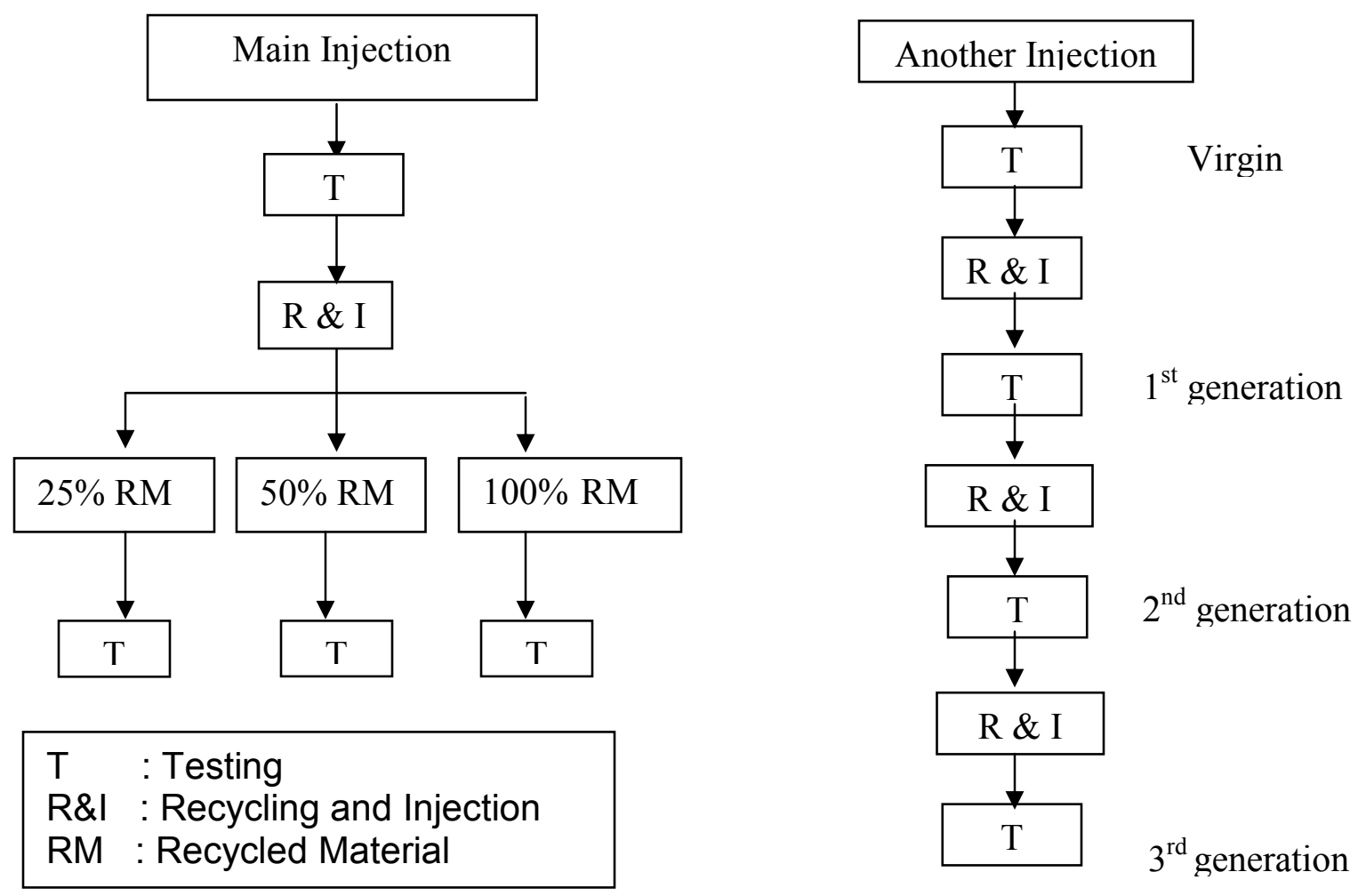

\subsection{Tests Procedure}

\subsubsection{Tensile test}

Tensile tests were carried out on universal Testing Machine Zwick Tensometer, 10 $\mathrm{KN}$ load cell. The cross-head speed was fixed at $50 \mathrm{~mm} / \mathrm{min}$ all over the experiments. Young's modulus (MPa), yield stress (MPa), break stress (MPa), elongation at yield (\%), and elongation at break (\%) were recorded. Five specimens were tested in each step and the average values were considered. Tests were carried out according to ASTM standards D638M-93 [7]. All the specimens were preconditioned for 48 hours and tested in an air-conditioned atmosphere at $23 \pm 2{ }^{\circ} \mathrm{C}$ and $50 \pm 6 \%$ relative humidity. The specimens' dimensions are shown in Fig. 6 .

\subsubsection{Impact test}

To determine the impact strength of HDPE, a Charpy pendulum impact testing machine for polymers (RKP50), was employed. The pendulum mass was $2.95 \mathrm{Kg}$ and the impact velocity was $3.834 \mathrm{~m} / \mathrm{s}$ with supporting span of $70 \mathrm{~mm}$. The machine is computerized, so the output time-energy curve can be printed out for each specimen. Tests were carried out according to ES 895-1967 [8]. All the specimens were tested in an air-conditioned atmosphere at $23+2{ }^{\circ} \mathrm{C}$ and $50+6 \%$ relative humidity. The impact strength was obtained in $\mathrm{kJ} / \mathrm{m} 2$ by dividing the energy used in breaking the specimen by its affected area. The specimens' dimensions are shown in Fig. 7. 

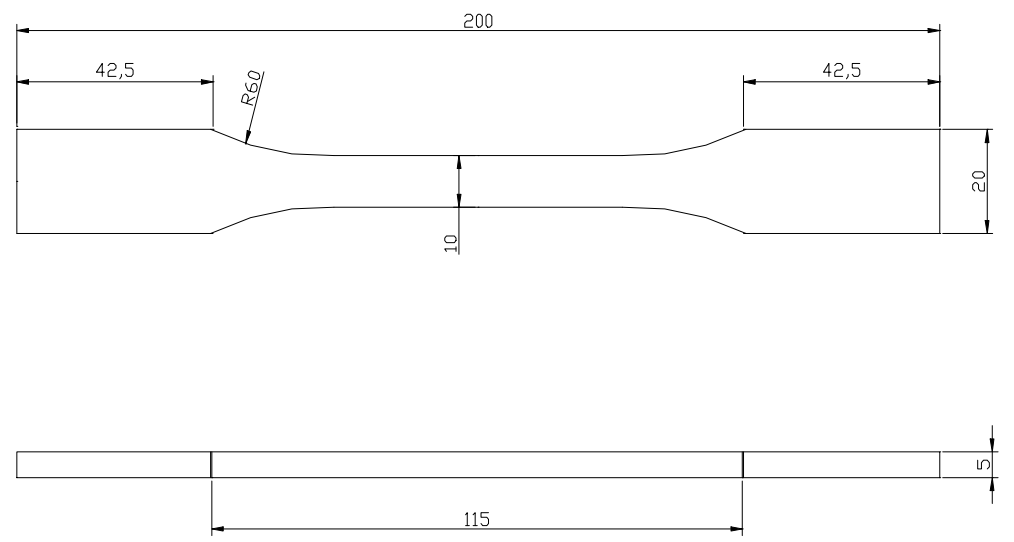

Fig. 6. Tensile test specimen

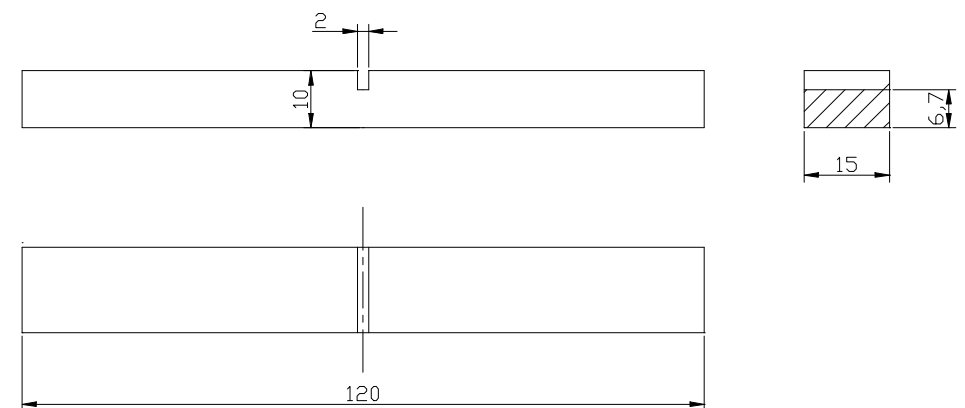

Fig. 7. Impact test specimen

\subsubsection{Creep test}

Plastics exhibit a similar shape of creep strain against time for constant stress and temperature as for metals. However, one distinct difference is the ability of plastics, being viscoelastic materials, to recover slowly over a period of time after the removal of the applied load. Thus the creep test was carried out to study the recovery due to the viscoelastic behaviour of HDPE by loading the specimens with constant stress of $7 \mathrm{MPa}$ for 10 hours and then removing the load suddenly. The strain-time curves were plotted showing an elastic strain recovery region followed by a time dependent recovery region and a plastic permanent deformation region, as shown in Fig. 8. 


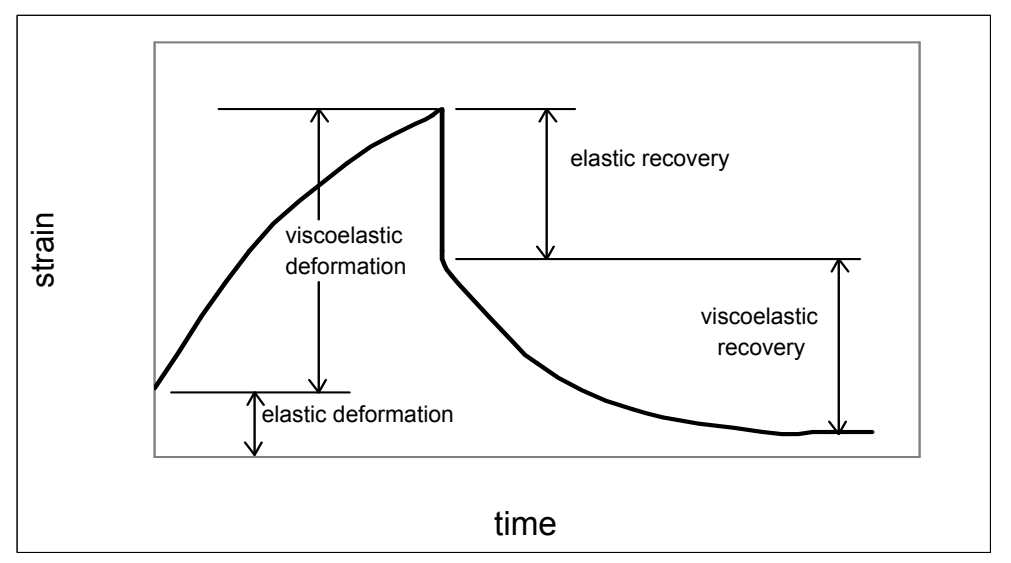

Fig. 8. Typical creep and recovery behaviour of a plastic [9]

The creep test rig, Fig. 9, consists of frame, specimen clamps, loading levers, elongation scale, and loading weights. This device can carry three specimens with different loads at the same time. The applied load at the lever end is magnified to the ratio of 10 at the specimen, Fig. 10. The same tensile test specimen configuration was used with a gauge length of $40 \mathrm{~mm}$ [10].

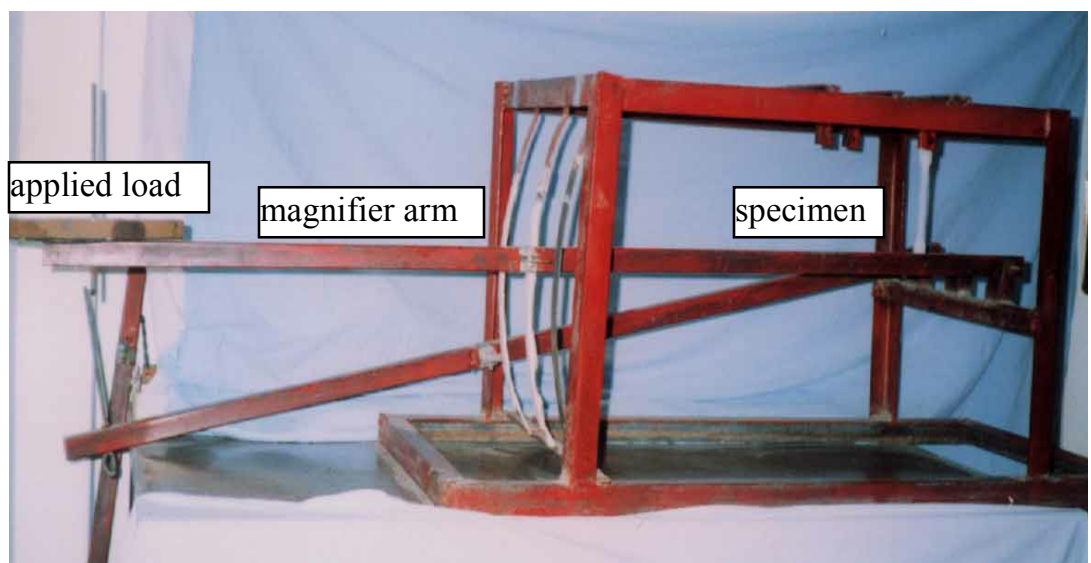

Fig. 9. The creep test rig

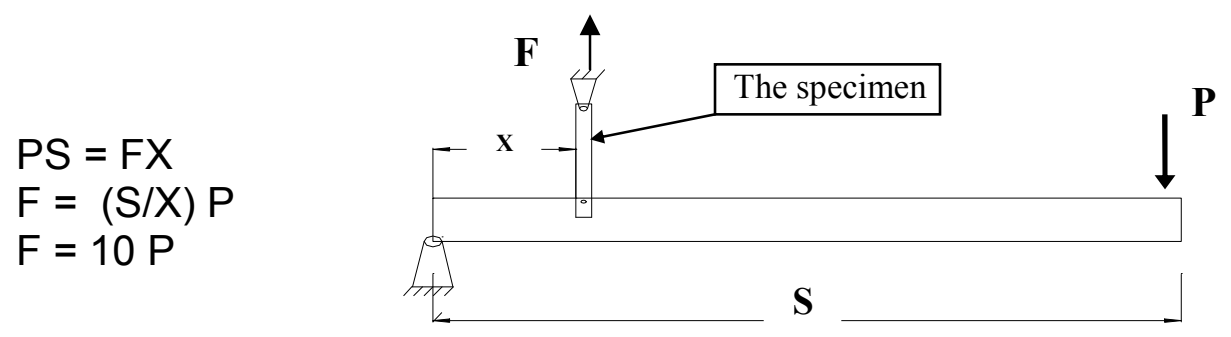

Fig. 10. Schematic drawing for loading the specimen on the creep test rig

\subsubsection{Density test}

The specimen weight was recorded before each test by using an electronic balance of $1 \mathrm{mg}$ sensitivity. The specimen then was submerged in oil which was poured out in a $100 \mathrm{~cm}^{3}$ vessel graduated to $1 \mathrm{~cm}^{3}$. The volume of the specimen was determined 
by subtracting the oil level record before and after submerging the specimen. The density was obtained in $\mathrm{g} / \mathrm{cm}^{3}$ by dividing the specimen weight by its volume. Five specimens were tested in each step and the average value was considered.

\section{RESULTS AND DISCUSSION}

\subsection{Effect of Recycled Material Percentage}

To study the effect of the recycled material content, a main injection for virgin material was carried out and tested. The average values and conditions for this injection are tabulated in Table 2.

Table 2. Results of virgin specimens

\begin{tabular}{|c|c|c|c|c|c|c|}
\hline & $\begin{array}{l}\text { Young's } \\
\text { modulus, } \\
\text { MPa }\end{array}$ & $\begin{array}{l}\text { Yield } \\
\text { strength, } \\
\mathrm{MPa}\end{array}$ & $\begin{array}{l}\text { Elongation } \\
\text { percentage, } \\
\%\end{array}$ & $\begin{array}{l}\text { Impact } \\
\text { strength, } \\
\mathrm{kJ} / \mathrm{m}^{2}\end{array}$ & $\begin{array}{l}\text { Creep } \\
\text { recovery } \\
\text { behaviour,\% }\end{array}$ & $\begin{array}{l}\text { Density } \\
, \mathrm{g} / \mathrm{cm}^{3}\end{array}$ \\
\hline $\begin{array}{l}\text { Average } \\
\text { value }\end{array}$ & 556 & 24.1 & 20 & 4 & $\begin{array}{l}\text { total } 80.26 \\
\text { time depend- } \\
\text { ent } 62\end{array}$ & 0.945 \\
\hline $\begin{array}{l}\text { No. of tested } \\
\text { specimens }\end{array}$ & \multicolumn{3}{|c|}{5} & 3 & 3 & 6 \\
\hline $\begin{array}{l}\text { Test temp- } \\
\text { erature, }{ }^{\circ} \mathrm{C}\end{array}$ & \multicolumn{4}{|c|}{$23 \pm 2$} & 31 & 34 \\
\hline $\begin{array}{l}\text { Relative } \\
\text { humidity, \% }\end{array}$ & \multicolumn{2}{|c|}{44} & \multicolumn{2}{|c|}{48} & 48 & 48 \\
\hline
\end{tabular}

It can be stated that the increase of recycled content increases the density of HDPE, Fig. 11. It means that the HDPE crystallinity could be raised by addition more recycled material to the virgin one. The variation of the injection temperatures from $160{ }^{\circ} \mathrm{C}$ for virgin material to $180{ }^{\circ} \mathrm{C}$ for $100 \%$ recycled content may affect the crystallinity of HDPE and may be responsible of this behaviour.

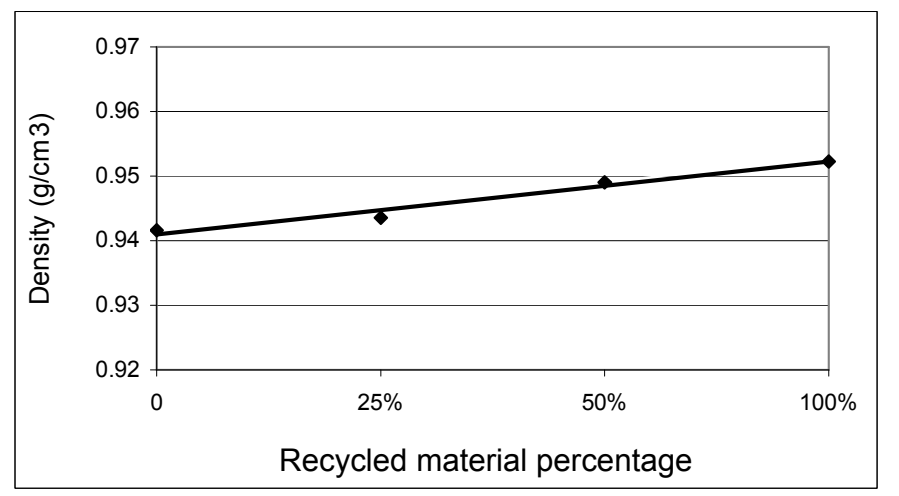


Fig. 11. Effect of recycled material percentage on the density

The variation of Young's modulus with the recycled content of HDPE is illustrated in Fig. 12. No significant effect for the recycled content on the elastic modulus. Its average value is $524 \mathrm{MPa}$.

Figure 13 shows the yield strength stability with variation of recycled material content where its value is nearly $24 \mathrm{MPa}$ for all ratios. The overall decrease at $100 \%$ recycled material content is about $2.5 \%$ from the virgin strength value.

The resulting elongation percentage is nearly constant of about $20 \%$ with the various contents of recycled material, Fig. 14. Despite the unhomogenity between the granulates size of recycled and virgin materials due to the crushing process, no deterioration is observed in the tensile properties.

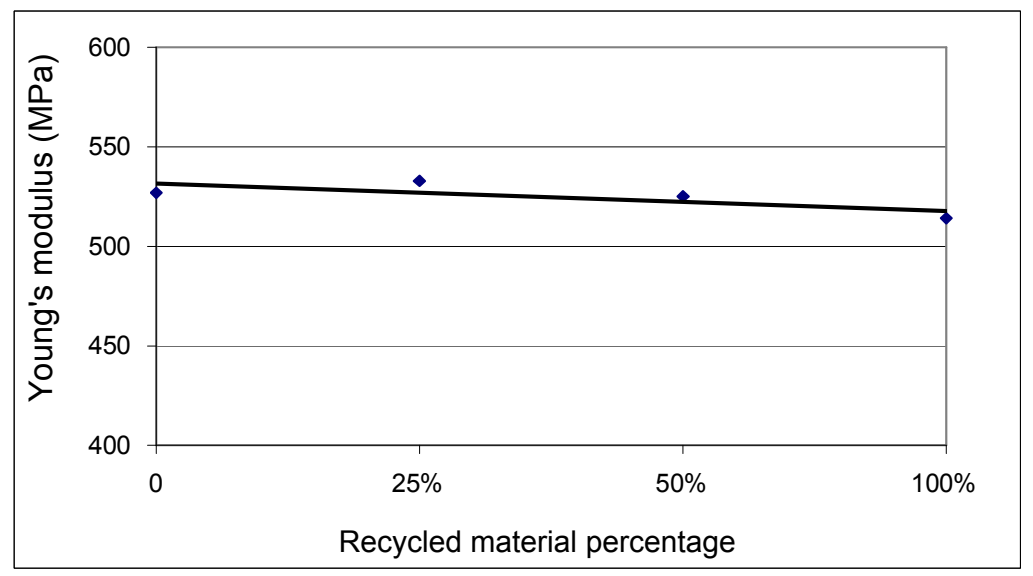

Fig. 12. Effect of recycled material percentage on the Young's modulus

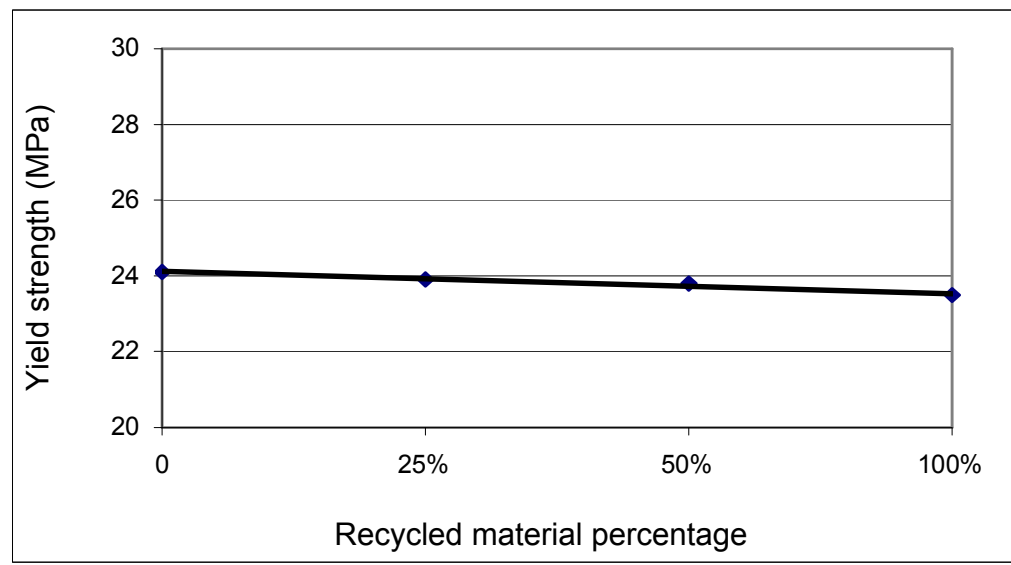

Fig. 13. Effect of recycled material percentage on the yield strength

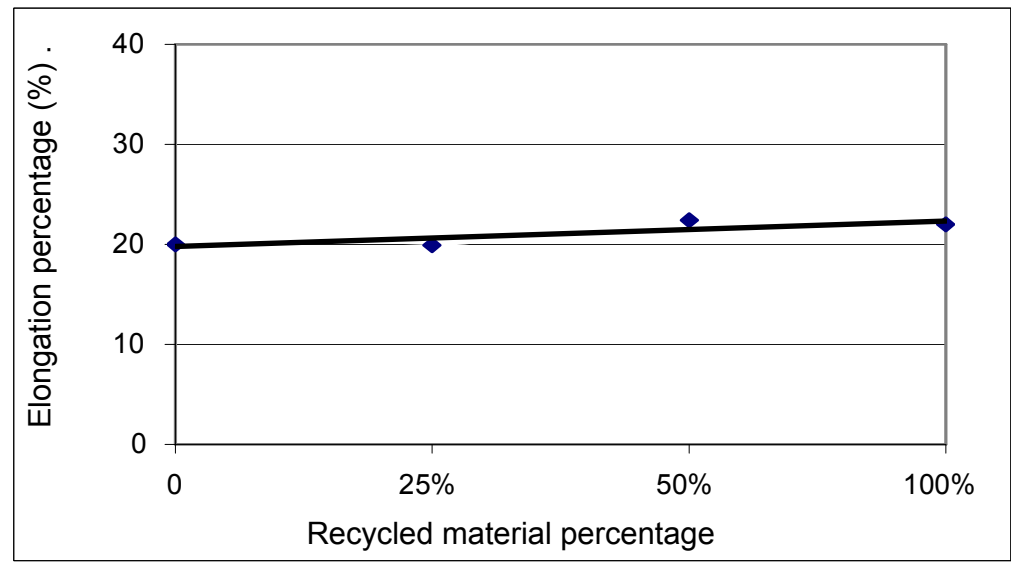


Fig. 14. Effect of recycled material percentage on the elongation percentage

The variation of the impact strength with the recycled material content is investigated and plotted in Fig. 15. The complete recycled material recorded impact strength of 3.37 times that of the virgin material. This improvement in impact performance conforms with previous study on polypropylene compounds which were carefully prepared to avoid the inclusions of impurities [11]. So, the HDPE toughness may be raised by blending with recycled material. It may be also noticed that increasing recycled material content from 25 to $50 \%$ has no significant effect on the impact strength.

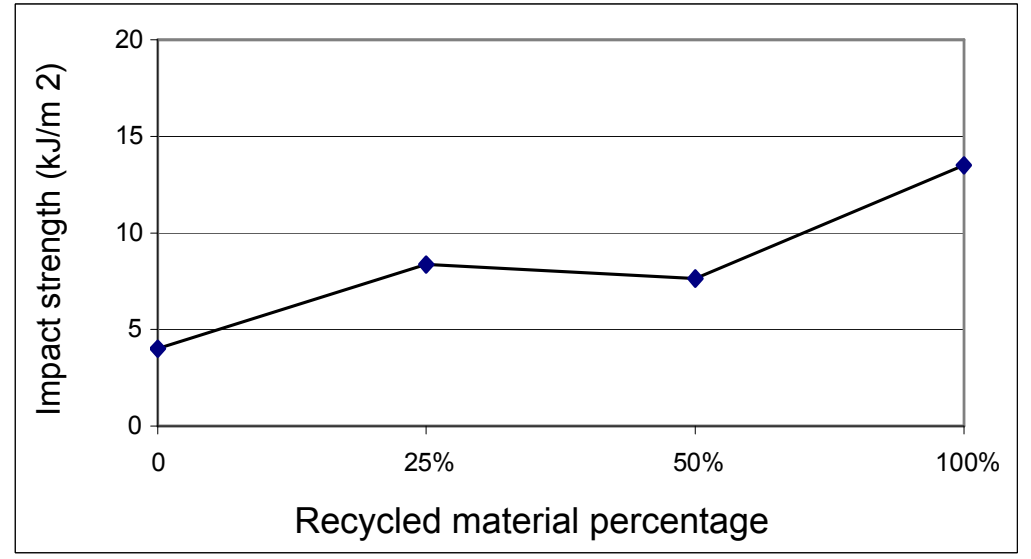

Fig. 15. Effect of recycled material percentage on the impact strength

The effect of increasing the content of the recycled material on creep properties is shown in Fig. 16. The addition of $25 \%$ recycled material decreases the maximum strain percentage by about $12 \%$ of the virgin material value. Further increase in the recycled material content results in an increase in the maximum strain percentage. This may be due to the unhomogenity between virgin and recycled HDPE granulates which may be responsible of inducing material with lower flow resistance; enhancing creep.

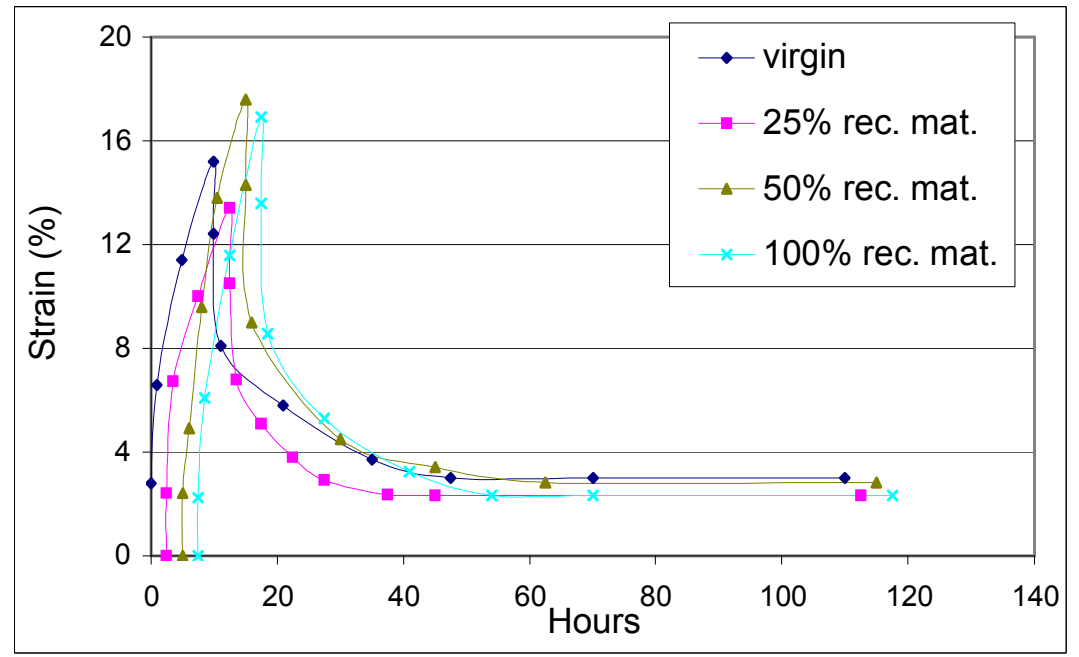

Fig. 16. Effect of recycled material percentage on the creep behaviour

The recovery behaviour means how much the loaded material returns to its original dimensions after removing the load of creep test. The recovery value of a material 
depends on its viscoelastic properties, the applied load, period of loading, and test conditions. As it was mentioned before, all of the tested specimens were exposed to a tensile stress of $7 \mathrm{MPa}$ for 10 hours before removing the load suddenly to investigate the material behaviour according to its viscoelastic properties.

The total recovery percentage is calculated by dividing the difference between maximum and minimum strains by the maximum strain. The minimum strain is the constant strain for 60 hours, it indicates the plastic or permanent deformation. By studying Fig. 17, the percentage of total recovery increases nearly linearly with increasing the recycled material content. At $100 \%$ recycled material the recovery percentage value exceed that of virgin material by about $7.5 \%$. The existence of recycled material content assists HDPE to return to its original shape.

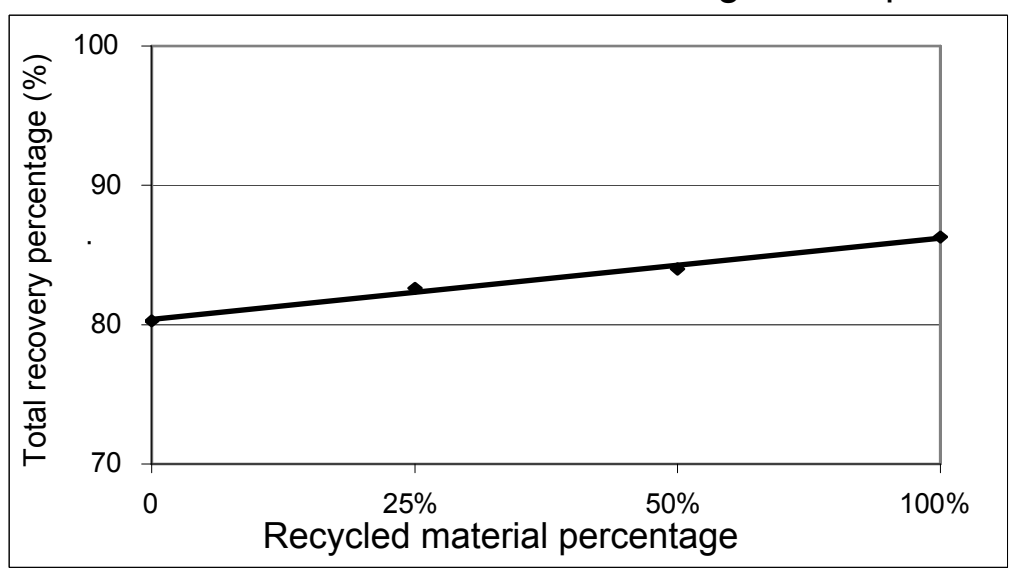

Fig. 17. Effect of recycled material percentage on the total recovery

With regard to Figs. 13 and 14, the decrease of yield strength and the increase of elongation percentage indicate improving the ductility of HDPE with increasing the recycled material content. This improving may be responsible of increasing the ability of HDPE to recover deformations.

\subsection{Effect of Recycling Generations}

To study the effect of the recycling generations, an independent main injection was carried out and tested before recycling. The average values and conditions for the virgin material of the second injection are tabulated in Table 3.

Table 3. Properties of virgin specimens

\begin{tabular}{|c|c|c|c|c|c|c|}
\hline & $\begin{array}{l}\text { Young's } \\
\text { modulus, } \\
\mathrm{MPa}\end{array}$ & $\begin{array}{l}\text { Yield } \\
\text { strength, } \\
\mathrm{MPa}\end{array}$ & $\begin{array}{l}\text { Elongation } \\
\text { percentage, } \\
\%\end{array}$ & $\begin{array}{l}\text { Impact } \\
\text { strength, } \\
\mathrm{kJ} / \mathrm{m}^{2}\end{array}$ & $\begin{array}{l}\text { Creep } \\
\text { recovery } \\
\text { behaviour,\% }\end{array}$ & $\begin{array}{l}\text { Density } \\
, \mathrm{g} / \mathrm{cm}^{3}\end{array}$ \\
\hline $\begin{array}{l}\text { Average } \\
\text { value }\end{array}$ & 505 & 24.25 & 21.7 & 83 & $\begin{array}{l}\text { total } 87.7 \\
\text { time depend- } \\
\text { ent } 55\end{array}$ & 0.944 \\
\hline $\begin{array}{l}\text { No. of tested } \\
\text { specimens }\end{array}$ & 5 & 3 & 3 & 3 & 3 & 3 \\
\hline $\begin{array}{l}\text { Test temp- } \\
\text { erature, }{ }^{\circ} \mathrm{C}\end{array}$ & \multicolumn{4}{|c|}{$23 \pm 2$} & 30 & 30 \\
\hline
\end{tabular}


As illustrated in Fig. 18, the higher reprocessing of HDPE the lower its density. It is expected that successive recycling operations cut the long polymer chains inducing more branched structure approaching that of lowdensity polyethylene [4].

As shown in Fig. 19, the modulus of elasticity decreases during the first cycle remains constant during $1^{\text {st }}$ to $3^{\text {rd }}$ generations. This effect may be explained by the decrease of the density which may cause a decrease in material crystallinity with repeating the recycling process. This trend is similar to the previous study on reinforced polyethylene [4]. by $10 \%$ from its virgin value and

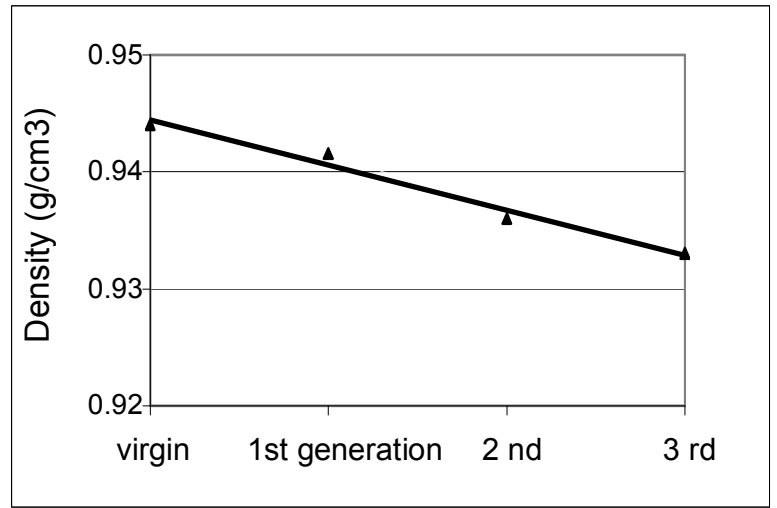

Fig. 18. Effect of recycling generations on the density

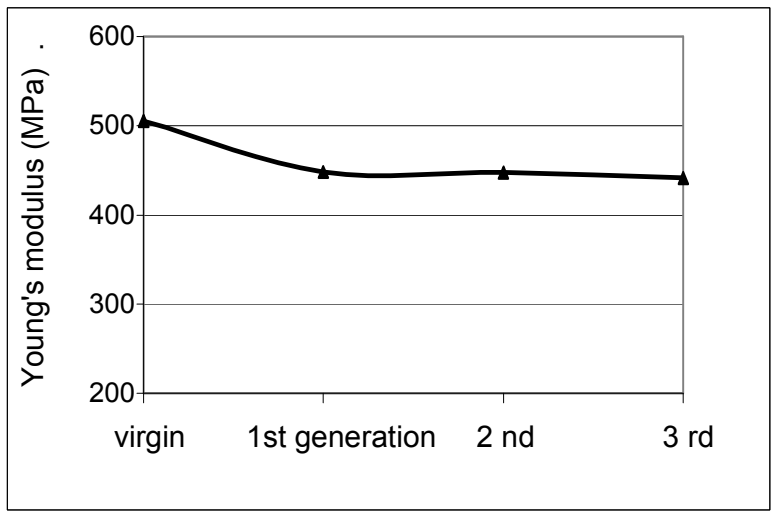

Fig. 19. Effect of recycling generations on the Young's modulus

\begin{tabular}{|l|l|l|l|l|}
\hline $\begin{array}{l}\text { Relative } \\
\text { humidity, \% }\end{array}$ & 46 & 48 & 56 & 52 \\
\hline
\end{tabular}

In respect of the yield strength, Fig. 20, no significant changes were recorded and the highest recorded variation is $4 \%$ from the virgin material strength.

Figure 21 shows the elongation percentage as a function of number of generations. It remains about $21 \%$ up to the $2^{\text {nd }}$ generation. After $3^{\text {rd }}$ generation a decrease to $a$ value of $17.5 \%$ is recorded. This behaviour may be attributed to the possible degradation through the recycling process caused by main chain scissions accompanied by an increase in the molecular weight. As it is known, the chains of material with high molecular weight can be tangled easily, and therefore the flow resistance goes high producing brittle material [12].
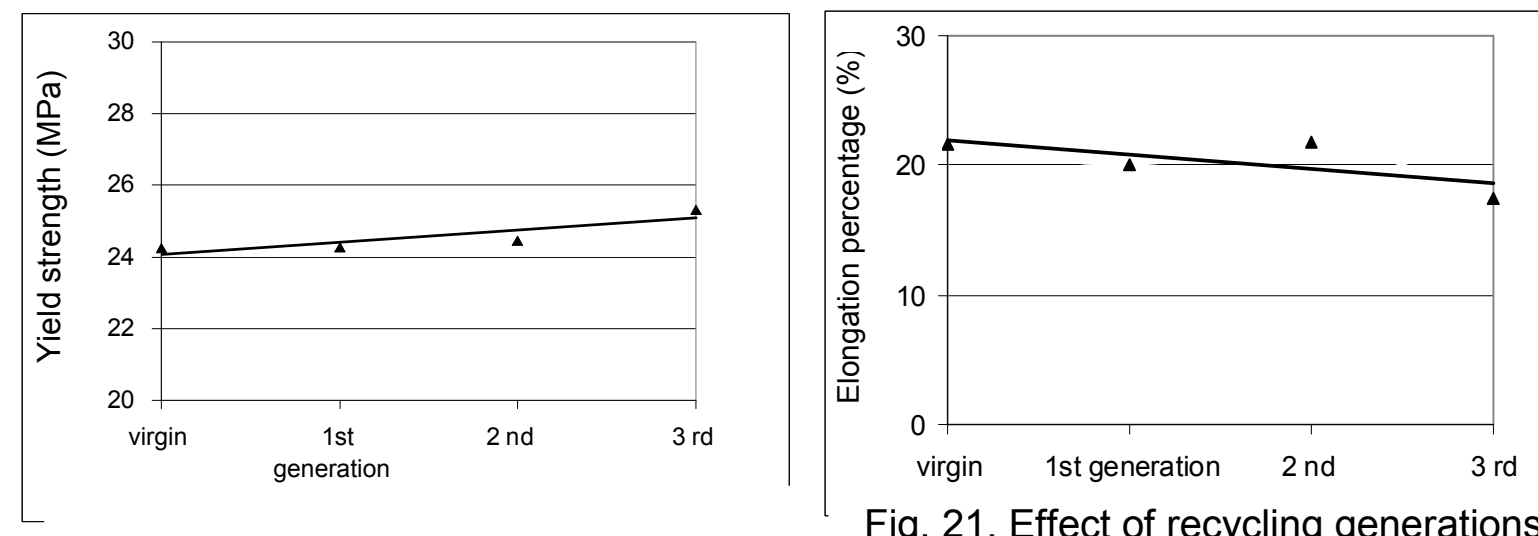

Fig. 21. Effect of recycling generations on the elongation percentage 
By studying Fig. 22, the first cycle greatly affects the impact strength by reducing it to seventh part of its value before recycling. The expected change in molecular weight of the recycled HDPE together with the change in injection conditions combine to reduce the impact strength of the mouldings. As the mouldings become more brittle the effect of any impurities present will become increasingly more important and would contribute to the sharp fall-off in the impact properties [11]. This behaviour nearly approaches a previous study on LDPE [5].

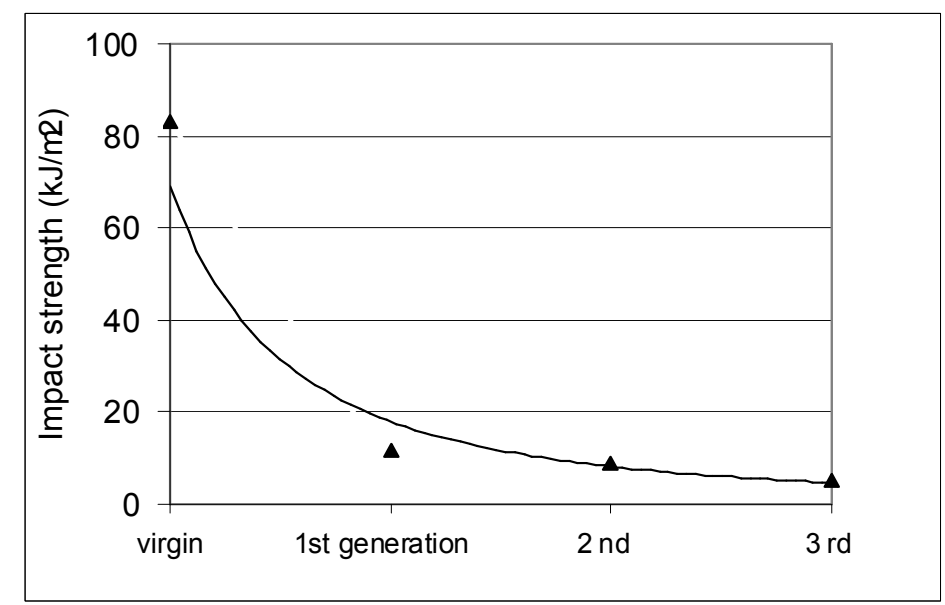

Fig. 22. Effect of recycling generations on the impact strength

The results of the recycling generations effect on the creep behaviour are obtained and plotted in Fig. 23. It can be noticed that the maximum strain percentage of the first generation was significantly affected by a drop of about $15 \%$ than that of the

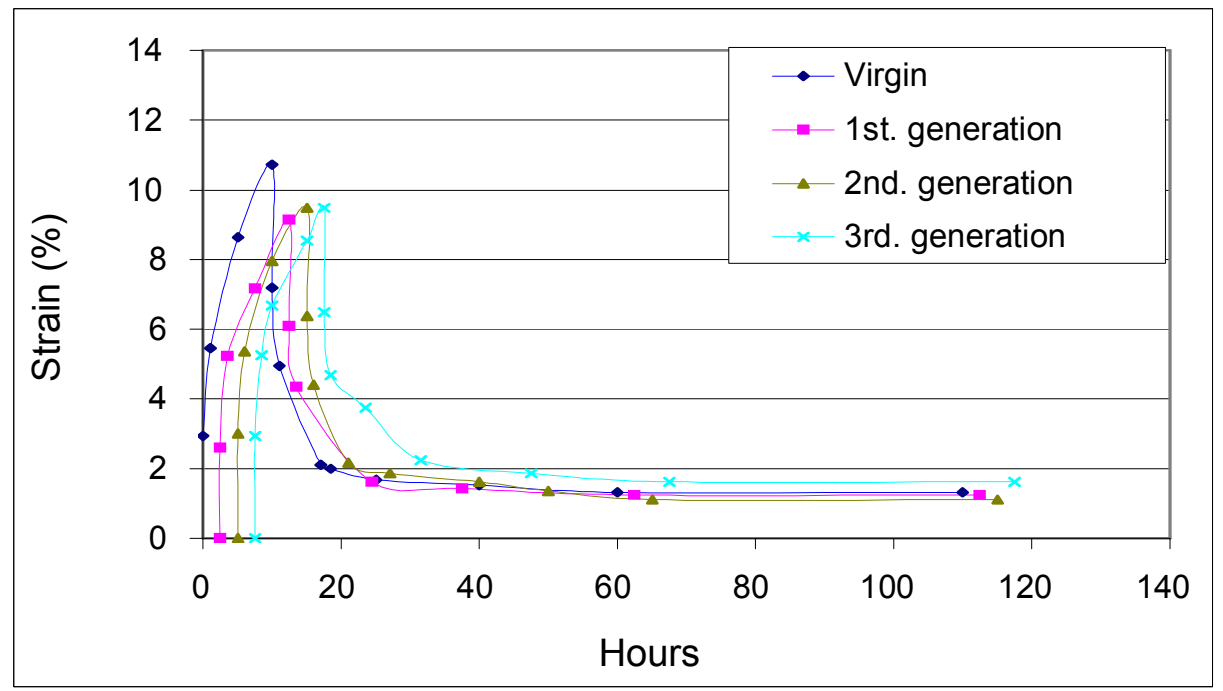

Fig. 23. Effect of recycling generations on the creep behaviour

virgin material. It may be attributed to the possible degradation through the recycling process causing polymer main-chain scissions and showing restrictions to chains mobility. However, the maximum strain stabilizes from the first to the third recycling generations. 
Figure 24 shows that the total recovery does not show real variation with the successive generations except after the third one; a reduction of about $6 \%$ is recorded after the last cycle. Which means that the material loses its ability to return to its original shape by recycling after the third time.

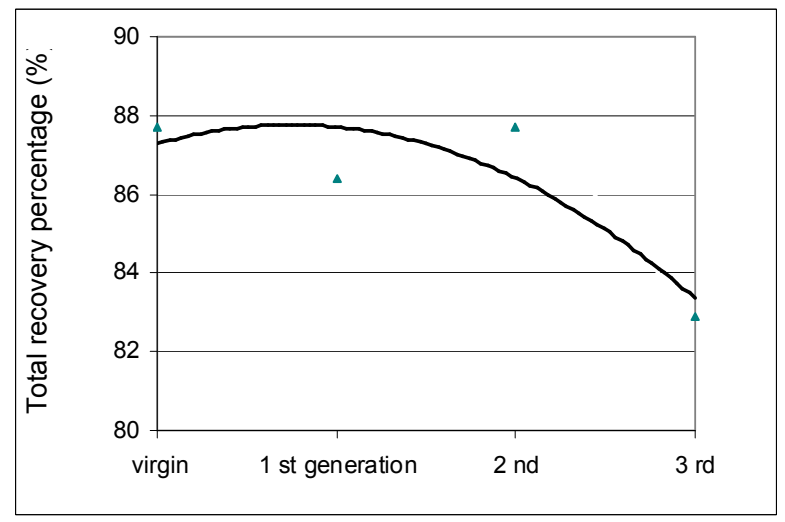

Fig. 24. Effect of recycling generations on the total recovery

\section{CONCLUSIONS}

From the obtained results of testing virgin, recycled, and recycled/virgin mixtures of HDPE specimens, the following conclusions can be drawn:

1 - With increasing the recycling generations the density, the modulus of elasticity, the percentage elongation, the impact strength, and the recovery percentage of the HDPE decrease while the tensile strength slightly increases. This decrease in properties can be explained by cutting the long chains (during repeated recycling) inducing more branched structure with lower density and crystallinity. Also, a possible degradation through the recycling process (caused by main chain scissions) may be responsible of this behaviour.

2- HDPE tends to be more brittle at the third generation. This tendency can be attributed to the change of injection conditions together with the expected increase in the molecular weight which leads to high flow resistance.

3- The density, the impact strength, and the recovery percentage increase with increasing the recycled material content while the modulus of elasticity, the percentage elongation, and the tensile strength remain almost constant. These results can be due to the injection conditions variation, mainly the temperature, with increasing the recycled material content which may increase the crystallinity and the density. The unhomogenity between virgin and recycled HDPE granulates may be responsible of inducing material with lower flow resistance; enhancing creep properties.

The effects of recycling are summarized in the following table:

\begin{tabular}{|l|l|l|l|l|l|l|}
\hline & Density & $\begin{array}{l}\text { Young's } \\
\text { modulus }\end{array}$ & $\begin{array}{l}\text { Yield } \\
\text { strength }\end{array}$ & $\begin{array}{l}\text { percentage } \\
\text { elongation }\end{array}$ & $\begin{array}{l}\text { Impact } \\
\text { strength }\end{array}$ & $\begin{array}{l}\text { Recovery } \\
\text { percentage }\end{array}$ \\
\hline $\begin{array}{l}\text { Recycling } \\
\text { generations }\end{array}$ & decrease & decrease & increase & decrease & decrease & decrease \\
\hline $\begin{array}{l}\text { Recycled } \\
\text { content }\end{array}$ & increase & constant & constant & constant & increase & increase \\
\hline
\end{tabular}


4- HDPE properties slightly changed with recycling, in the scope of the present work, which shows that following traditional rules, which recommend a limited content of recycled material to be added to the virgin material, is not a good way in general and may be conservative and more recycled material can be added without having a significant effect on the mechanical properties of some polymers such as HDPE.

5- Any acceptable deterioration in the mechanical properties of HDPE due to recycling process may be covered by a design factor.

6- Recycled plastics as HDPE are not low performance materials. They may possess better properties than some other materials and better understanding of the recycled plastics behaviour will increase the demand for recycled materials which will help in protecting the environment and in saving the raw materials.

\section{REFERENCES}

[1] Richardson, T.L., "Recycling", Microsoft, Encarta, Encyclopedia, (1999).

[2] Nabil, M., "Plastics Waste Management: Disposal, Recycling, and Reuse", Canadian Plastics Institute, Toronto, Canada, Marcel Dekker Incorporation, (1992).

[3] Corish, P.J., "Concise Encyclopedia of Polymer Processing and Applications", Pergamon Press, (1992).

[4] Harold, "Effect of Recycling on Material Properties of PET at Various Recycling Ratios and Recycling Generations", M. Sc. Thesis, University of Buertorico, (2003).

[5] Khattab, A.A. and ElZoghby, A.A., "Effect of Recycling on the Mechanical Properties of Low Density Polyethylene", Journal of Engineering and Applied Science, v 45 n4, (1998), pp. 533-547.

[6] Smith, W.F., "Principles of Materials Science and Engineering", Second Edition, McGraw Hill, New York, (1990).

[7] ASTM Standards, "Standard Test Method for Tensile Properties of Plastics (Metric)", ASTM D638M - 93, (1993).

[8] Egyptian Standards, "Determination of Impact Properties of Plastics", ES 895, (1967).

[9] Crawford, R.J., "Plastics Engineering", Third Edition, The Queen's University of Belfast, (1998).

[10] Naga S.A.R., Raafat, M.G., Bekheet, N. and Afifi, A., "Effect of Temperature, Cross Head Speed, and Duration of Load on the Mechanical Properties of PVC Polymeric Material", Military Technical College, 8th International Conference on Eurospace Sciences and Aviation Technology, Cairo, Egypt, (1999).

[11] Derfel, W. and Michael, B., "The Effect of Recycled Plastic and Compound Additives on the Properties of an Injection-Moulded Polypropylene Copolymer", Journal of Materials Science, v15, (1980), pp. 2843-2860.

[12] Lozano, M.J., Rodriguez, M.T., Gonzalez, E.A., and Villalpando, J., "Physical Mechanical Properties and Morphological Study on Nylon-6 Recycling by Injection Molding", Journal of Applied Polymer Science, v 76, (2000), pp. 851858. 